\title{
INUNDATION FLOW VELOCITY OF TSUNAMI ON LAND AND ITS PRACTICAL USE
}

\author{
Hideo Matsutomi ${ }^{1}$, Kensuke Okamoto ${ }^{2}$ and Kenji Harada ${ }^{3}$
}

\begin{abstract}
Based on field data of inundation depth and inundation flow velocity $u$ estimated using Bernoulli's theorem and inundation depth, fundamental characteristics of relationship between inundation flow velocity and inundation depth are examined. Velocity coefficient $C_{v}\left(=u / \sqrt{2 g\left(h_{f}-h_{r}\right)}\right.$ where $g$ is gravitational acceleration, $h_{f}$ and $h_{r}$ are inundation depths at the front and the back of structure such as a rectangular building with vertical walls respectively) implicitly included in the relationship is examined through steady flow experiments. As the result, $C_{v}=0.6$ is recommended as its simple and practical value. By using the relationship and $C_{v}=0.6$, two simple and practical relationships are presented for two cases where inundation flow velocity exerts the largest or the smallest fluid force on structures. Fundamental characteristics of waterline (tsunami-trace) distribution around a square pillar model are also examined through steady flow experiments. Examples of tsunami-trace distribution around building in the 2009 Samoa Earthquake tsunami are presented, and compared with those by steady flow experiments. It is confirmed through the comparison and examination that the tsunami-trace distributions around buildings by the field survey are consistent with those by the steady flow experiments and contain information such as inundation flow direction, velocity and fluid force at the maximum incident inundation depth, and strength of buildings. Variation coefficient C.V. of inundation flow velocity caused by the measured point difference at the front and the back of building is also examined. In addition, based on the above results of inundation flow velocity, the existing simple and practical judgment criterion for the degree of damage to buildings is re-examined, and it is confirmed that newly proposed judgment criterion for the degree of damage to wooden buildings is consistent with the tsunami fragility curve for Japanese wooden buildings by Koshimura et al.
\end{abstract}

Keywords: tsunami; field survey; hydraulic experiments; inundation flow velocity; degree of damage to buildings

\section{INTRODUCTION}

Information on inundation flow velocity $u$ of tsunami on land is necessary to grasp practical sides of tsunami damage (Shuto et al. 2007), estimate fluid force acting on individual structures (Iizuka and Matsutomi 2000), moving velocity and collision force of floating objects (Matsutomi 1999; Matsutomi 2009a; Matsutomi et al. 2009), and derive judgment criterion for the degree of damage to buildings. However, it is difficult to estimate the velocity, because the tip of inundation flow is mathematically a singular point, and the velocity is affected by many factors such as inundation depth, water surface slope, bottom slope, bottom roughness, and distance from shoreline (a process of tsunami run-up and definition of tsunami technical terms and parameters in this study are shown in Fig. 1). Although use of numerical simulation is considered as a solution to this difficulty, it takes a great deal of labor, and the accuracy of results is not so high for the labor involved.

In light of the above circumstances, a simple and practical method for estimating inundation flow velocity had been developed by Matsutomi et al. (1994, 1998), using field and experimental data of inundation depth and inundation flow velocity under the assumption of quasi-steady flow. In the method, inundation flow velocity can be simply estimated from the difference of inundation depths at the front and the back of structure such as a rectangular building with vertical walls, based on

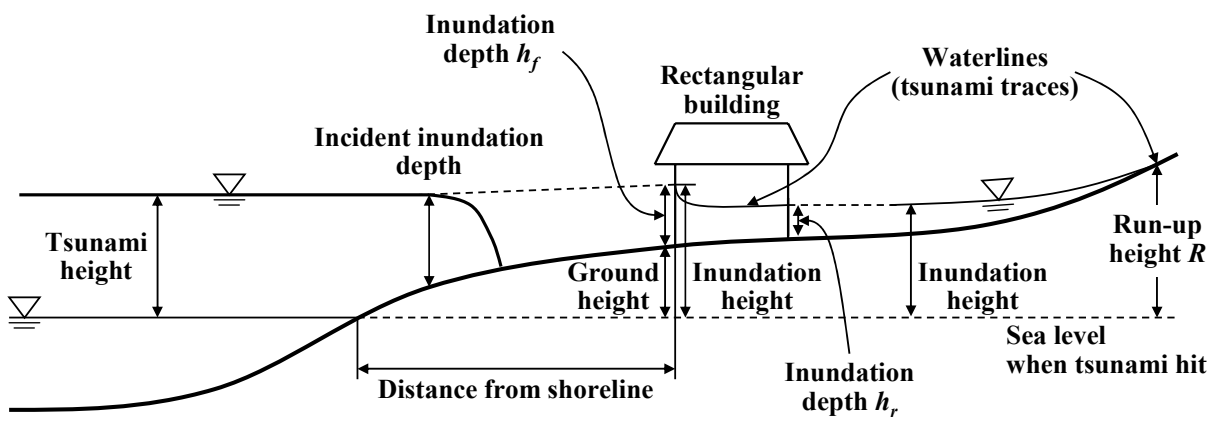

Figure 1. A process of tsunami run-up and definition of tsunami technical terms and parameters.

\footnotetext{
${ }^{1}$ Department of Civil and Environmental Engineering, Akita University, 1-1 Tegata Gakuen, Akita, 010-8502, Japan

${ }^{2}$ Department of Civil Engineering, Itogumi Construction Co., Ltd, 4-4, Chuo, Sapporo, 060-8554, Japan

${ }^{3}$ Department of Civil and Environmental Engineering, Saitama University, Shimo-Okubo, Sakura, 338-8570, Japan
} 
Bernoulli's theorem. However, there still remain problems to be examined in the method, because the following two points are uncertain: (1) velocity coefficient $C_{v}\left(=u / \sqrt{2 g\left(h_{f}-h_{r}\right)}\right.$ where $g$ is gravitational acceleration, $h_{f}$ and $h_{r}$ are inundation depths at the front and the back of structure, respectively), and (2) tsunami-trace (waterline) distribution around/on a structure or other object such as a small hill. Therefore, how to select proper parts of tsunami-trace on walls of structure to obtain proper data is still unsettled. Relationship among the maximum incident inundation depth and inundation depths at the front and the back of structure is also unknown.

In this study, therefore, simple and practical relationship between inundation flow velocity and inundation depth is examined through field and experimental data of those under the assumption of quasi-steady flow. Simple and practical relationship among the maximum incident inundation depth $h$, inundation depths $h_{f}$ and $h_{r}$ is also examined. Moreover, the velocity coefficient $C_{v}$ is examined through steady flow experiments. Tsunami-trace distributions around buildings by field surveys are compared with waterline distributions around a building model by steady flow experiments. Variation coefficient $C . V$. (=standard deviation/ mean value) of inundation flow velocity caused by the measured point difference at the front and the back of building is examined. In addition, based on the above simple and practical relationships, the existing simple and practical judgment criterion for the degree of damage to buildings (Iizuka and Matsutomi 2000) is re-examined, and newly proposed judgment criterion is compared with the tsunami fragility curve for Japanese wooden buildings by Koshimura et al. (2009).

\section{INUNDATION FLOW VELOCITY BASED ON FIELD SURVEYS}

Data on inundation depth and inundation flow velocity in heavily affected areas of tsunamis have been collected to estimate strength of buildings and establish criterion for judging the degree of damage to buildings (e.g., Matsutomi and Shuto 1994). The strength of buildings and the criterion are useful, for example, to estimate tsunami damage due to the prospective tsunamis such as the Tokai, Tonankai and Nankai Earthquake tsunamis in Japan, and build appropriate refuge buildings on the low-lying coastal areas.

Figures $2 \mathrm{a}$ and $2 \mathrm{~b}$ show relationships between nondimensionalized inundation depth $h_{f} / R$ or $h_{r} / R$ and inundation flow velocity $u / \sqrt{g R}$, where $R$ is inundation height or nearest tsunami run-up height from the sea level when the first tsunami hit the coast nearest to each surveying place of inundation depth and $u$ is estimated by the following equation (Bernoulli's theorem) under the assumption of quasi-steady flow:

$$
u=\sqrt{2 g\left(h_{f}-h_{r}\right)}
$$

Symbols in the figures are data collected from recent tsunamis, including the 2010 Chile Earthquake tsunami (Matsutomi et al. 2010). Almost all data were collected at places away from shoreline and as flat as possible, although the distance from shoreline to each place was not measured in most cases.

It is recognized from Figs. $2 \mathrm{a}$ and $2 \mathrm{~b}$ that the inundation flow velocity shows somewhat systematic trend to form a group at each tsunami event. This is probably because field surveys and/or buildings are restricted within narrow limits, and the scale of each tsunami is different.

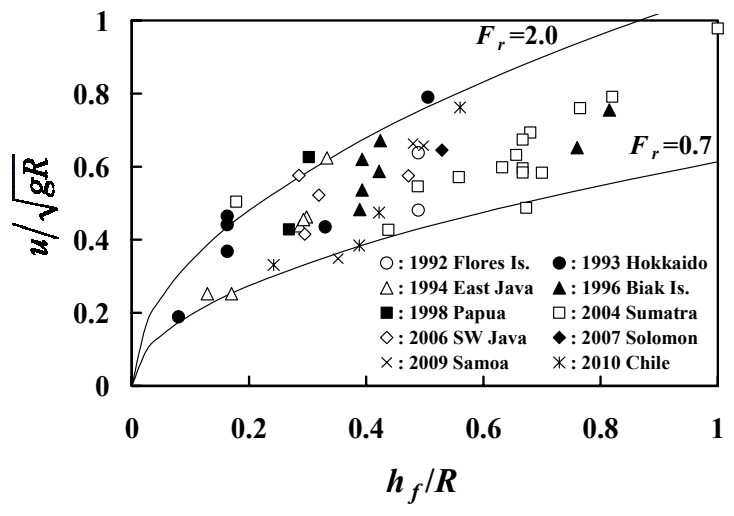

(a) Case used inundation depth on the front side

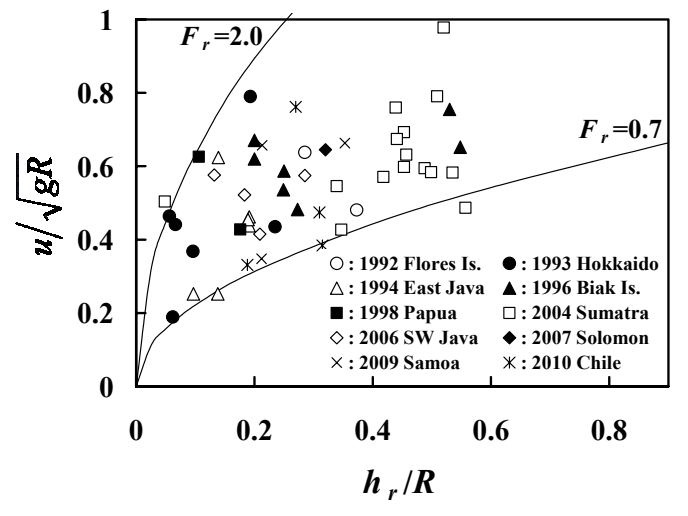

(b) Case used inundation depth on the back side

Figure 2. Relationship between nondimensionalized inundation depth $h_{f} / R$ or $h_{r} / R$ and inundation flow velocity $u / \sqrt{g R}$ in the case without taking account of energy loss $\left(C_{v}=1.0\right)$. 
Solid lines in Figs. $2 \mathrm{a}$ and $2 \mathrm{~b}$ are envelopes for field data and also theoretical curves expressed by Eqs. 2 and 3 (Matsutomi and lizuka 1998) with the velocity coefficient $C_{v}=1.0$ and Froude number $F_{r}$, defined by $F_{r}=u / \sqrt{g h_{r}},=0.7$ or 2.0 .

$$
\begin{gathered}
\frac{u}{\sqrt{g R}}=\sqrt{\frac{2 C_{v}^{2} F_{r}^{2}}{F_{r}^{2}+2 C_{v}^{2}}} \sqrt{\frac{h_{f}}{R}} \\
\frac{u}{\sqrt{g R}}=F_{r} \sqrt{\frac{h_{r}}{R}}
\end{gathered}
$$

The velocity coefficient $C_{v}$ from an engineering viewpoint is discussed later, based on steady flow experiments.

Upper envelopes in Figs. 2a and 2b, whose inundation flow velocities exert the largest fluid force, are expressed as:

$$
\begin{gathered}
\frac{u}{\sqrt{g R}}=1.1 \sqrt{\frac{h_{f}}{R}} \\
\frac{u}{\sqrt{g R}}=2.0 \sqrt{\frac{h_{r}}{R}}
\end{gathered}
$$

Lower envelopes in Figs. 2a and 2b, whose inundation flow velocities exert the smallest fluid force, are expressed as:

$$
\begin{gathered}
\frac{u}{\sqrt{g R}}=0.6 \sqrt{\frac{h_{f}}{R}} \\
\frac{u}{\sqrt{g R}}=0.7 \sqrt{\frac{h_{r}}{R}}
\end{gathered}
$$

\section{TSUNAMI-TRACE DISTRIBUTION AROUND BUILDING}

Tsunami-trace distributions around buildings seem to contain information such as inundation flow direction, velocity and fluid force at the maximum incident inundation depth, and strength of buildings. Therefore, it is worth examining fundamental characteristics of tsunami-trace distributions around buildings and comparing the tsunami-trace distributions by field surveys with waterline distributions around a building model by laboratory experiments.

\section{Laboratory Experiments}

Laboratory experiments under steady flow conditions were carried out to examine fundamental characteristics of waterline distribution around a square pillar model which is a model of building and the velocity coefficient $C_{v}$. The experiments correspond to those under tsunamis with infinite wave period. There are two reasons why the steady flow experiments were carried out are: (1) it is difficult to measure the instantaneous waterline distribution under unsteady flow conditions, and (2) number of unknown factors in steady flow experiments is less than that in unsteady flow experiments.

Experimental flume used is schematically shown in Fig. 3. The flume is $1.0 \mathrm{~m}$ wide, $0.15 \mathrm{~m}$ high and $8.0 \mathrm{~m}$ long with transparent vinyl chloride sidewalls and bed. As the wall at the downstream end of the flume is removed, flows can pass through there without accompanying any reflection phenomena.

Dimensions of the building model made of transparent vinyl chloride are $0.1 \mathrm{~m}$ wide, $0.1 \mathrm{~m}$ high and $0.1 \mathrm{~m}$ long. The model was placed alone at the center and $4.5 \mathrm{~m}$ (Cases 1 and 2 in Table 1) or 4.1 $\mathrm{m}$ (Case 3 in Table 1) downstream from the upstream end of the flume, as shown in Fig. 3. As the location of the model was fixed in each case of the experiments, examination of the effect of distance from shoreline on inundation flow velocity is out of scope of this study.

A point gauge and a propeller-type current meter were used to measure water depth and flow velocity, respectively. Locations of five cross sections indicated by the broken lines along which water depth and flow velocity were measured are shown in Fig. 3. They were measured at intervals of 3-4 cm 


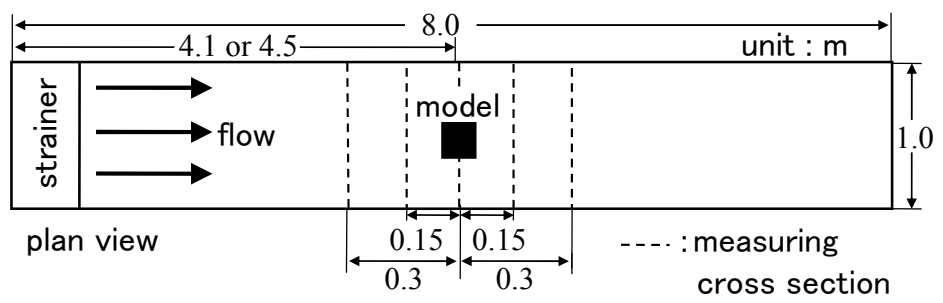

Figure 3. Experimental flume, arrangement of a building model and locations of measuring cross sections (broken lines) in the steady flow experiments.

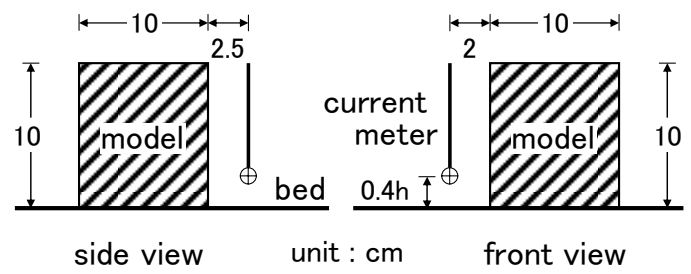

Figure 4. Details of arrangement of current meter, where the hatched are the square pillar model and $h$ is water depth in the case without the square pillar model.

Table 1. Experimental conditions of steady flow.

\begin{tabular}{|c|c|c|c|c|c|}
\hline & $Q\left(\mathrm{~cm}^{3} / \mathrm{s}\right)$ & $S$ & $u_{0}(\mathrm{~cm} / \mathrm{s})$ & $h_{0}(\mathrm{~cm})$ & $F_{r 0}$ \\
\hline Case 1 & 7100 & $1 / 2900$ & 25.9 & 2.75 & 0.5 \\
\hline Case 2 & 8500 & $1 / 320$ & 38.8 & 2.18 & 0.84 \\
\hline Case 3 & 14700 & $1 / 127$ & 64.6 & 2.27 & 1.37 \\
\hline
\end{tabular}

within $30 \mathrm{~cm}$ from the model and at intervals of $10 \mathrm{~cm}$ elsewhere along two cross sections on the upstream side of the model and at intervals of $2 \mathrm{~cm}$ within $30 \mathrm{~cm}$ from the model and at intervals of 10 $\mathrm{cm}$ elsewhere along three cross sections on the downstream side of the model. The current meter was installed near the downstream corner of the model to measure time history of inundation flow velocity. Probe of the current meter (diameter of propeller $=0.3 \mathrm{~cm}$ ) was set at the height of $40 \%$ of water depth in the case without the model from the flume bed at its arranged place in each experimental condition. Details of arrangement of the current meter are shown in Fig. 4. Height of waterline from the flume bed around the model was also measured by the point gauge at intervals of $1 \mathrm{~cm}$.

Experimental conditions are summarized in Table 1, where $Q$ is discharge, $S$ is bed slope of the flume, $h_{0}$ and $u_{0}$ are, respectively, mean water depth and flow velocity of steady flow (hereinafter 'uniform flow') along the middle cross section passing the center of the model intended to arrange in the flume and $F_{r 0}$ is Froude number defined by $F_{r 0}=u_{0} / \sqrt{g h_{0}}$. It should be noted that the definition of Froude number is different from that in the field surveys.

Waterline distribution around square pillar model and velocity coefficient $\boldsymbol{C}_{v}$

Figure 5 shows waterline distributions around the square pillar model, where $h$ is the height of waterline from the flume bed, $y$ is the distance axis along the front side (left figure) with origin at the left corner or the back side (right figure) with origin at the right corner of the model and nondimensionalized by the width $W$ of the model, $x$ is the distance axis along the right side with origin at the upstream corner of the model and nondimensionalized by the length $L$ of the model, and $B$ is the breadth of the flume. It can be recognized from the figure that:

- $h_{f} / h_{0}$ becomes large and $h_{r} / h_{0}$ becomes small as Froude number, defined by $F_{r 0}=u_{0} / \sqrt{g h_{0}}$, becomes large.

- $h_{r} / h_{0}$ is less than 1.0 and gradually approaches to 1.0 as Froude number is less than 1.0 (subcritical flow) and becomes smaller.

- $h_{r} \cong h_{0}$ when Froude number is much less than 1.0 such as the case of $F_{r 0}=0.5$ shown in Fig. 5. In this case, the maximum incident inundation depth at a building can be roughly estimated by measuring $h_{r}$.

Table 2 shows the velocity coefficient $C_{v}$ estimated using Eq. 8 and experimental data on $u_{0}, h_{f}$ and $h_{r}$, where $\lambda=100 \times(1-$ occupation ratio of building model in the transverse direction of the flume). 


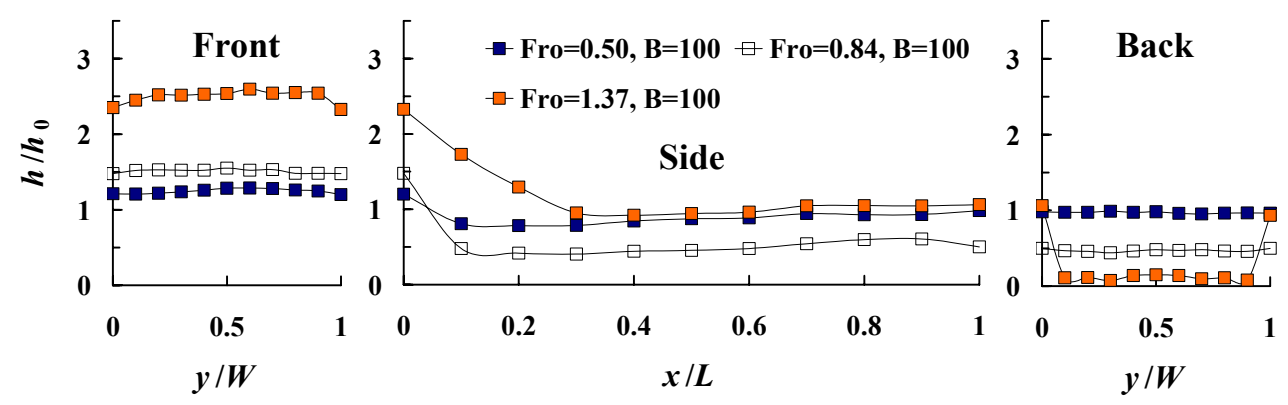

Figure 5. Waterline distributions around a square pillar model.

Table 2. Velocity coefficient $C_{v}$ in the steady flow experiments.

\begin{tabular}{|c|c|c|c|}
\hline Shape & $\lambda(\%)$ & $F_{r 0}$ & $C_{v}$ \\
\hline \multirow{2}{*}{$\begin{array}{c}\text { Square } \\
\text { pillar }\end{array}$} & 90 & 0.5 & 0.66 \\
\cline { 2 - 4 } & 90 & 0.84 & 0.58 \\
\cline { 2 - 4 } & 90 & 1.37 & 0.63 \\
\hline
\end{tabular}

$$
C_{v}=\frac{u_{0}}{\sqrt{2 g\left(h_{f}-h_{r}\right)}}
$$

where $u_{0}$ is adopted as $u$ in the original definition of $C_{v}$. The velocity coefficients range $0.58-0.66$ (mean=0.62) for the square pillar model.

\section{Simple and practical relationship between inundation flow velocity and inundation depth}

In actual tsunami flood plains, most objects such as structures and small hills usually stand alone. The steady flow experiments indicate that the velocity coefficient $C_{v}$ for the square pillar model ranges 0.58-0.66 (mean=0.62). According to the results of inundation flow experiments (Matsutomi and Okamoto 2010), the velocity coefficient for the square pillar model is smaller than that in the steady flow experiments. Therefore, assuming very severe case to structures, and taking the wave period of tsunamis into consideration, $C_{v}=0.6$ is recommended as its simple and practical value. As this result, inundation flow velocity $u$ can be estimated using the following equation:

$$
u=0.6 \sqrt{2 g\left(h_{f}-h_{r}\right)}
$$

The following two simple and practical relationships between inundation flow velocity and inundation depth are also found by using Eqs. 4-7. That exerting the largest fluid force is

$$
u=0.66 \sqrt{g h_{f}}=1.2 \sqrt{g h_{r}}
$$

and that exerting the smallest fluid force is

$$
u=0.36 \sqrt{g h_{f}}=0.42 \sqrt{g h_{r}}
$$

When Froude number is much less than 1.0, Eqs. 10 and 11 respectively become

$$
\begin{gathered}
u=0.66 \sqrt{g h_{f}}=1.2 \sqrt{g h_{r}} \cong 1.2 \sqrt{g h} \\
u=0.36 \sqrt{g h_{f}}=0.42 \sqrt{g h_{r}} \cong 0.42 \sqrt{g h}
\end{gathered}
$$

Using these simple and practical relationships, the maximum and the minimum inundation flow velocities can be estimated only from inundation depths at the front and/or the back of building during the emergency tsunami field surveys, or those written in the record of historical tsunamis.

\section{Field Surveys}

At 06:48:10 (local time at epicenter), Sep. $29^{\text {th }} 2009$, a major earthquake with the moment magnitude of $M_{w}=8.1$ occurred $199 \mathrm{~km} \mathrm{SW}\left(15.509^{\circ} \mathrm{S}, 172.034^{\circ} \mathrm{W}\right)$ from Pago Pago in Tutuila Is., 


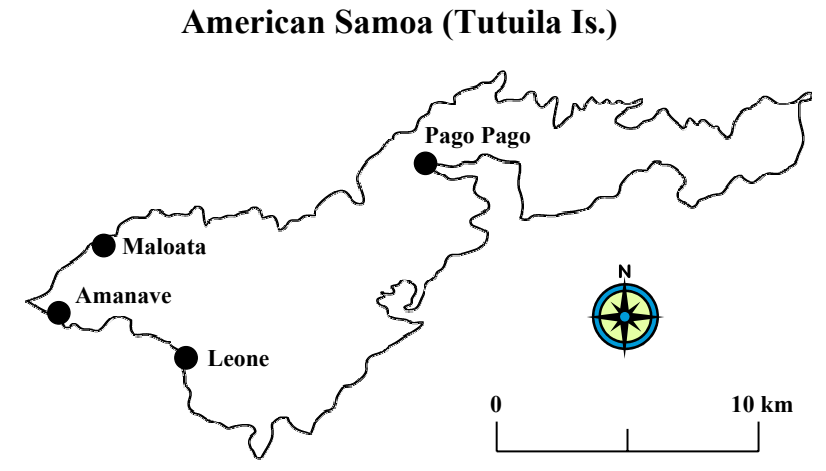

Figure 6. Tsunami field survey areas in Tutuila Is., American Samoa.

American Samoa and generated a huge tsunami (USGS, 2009). The tsunami hit Samoa, American Samoa and Tonga, and heavily damaged lives, properties, buildings and infrastructures. Number of deaths reached more than 226 (Samoa 183; American Samoa 34; Tonga 9), as of Dec. $18^{\text {th }} 2009$. Tsunami field survey whose results are reported hereinafter was carried out at Maloata, Amanave, Leone and Pago Pago in Tutuila Is. from Oct. 15-18 ${ }^{\text {th }}$ 2009. Locations of the areas are shown in Fig. 6.

\section{Tsunami-trace heights and their distribution}

Examples of tsunami-trace heights and their distribution (bold solid lines) around a building are shown in Figs. 7(a)-(d), where numeral is inundation height and numeral in parenthesis is inundation depth. Arrows in the lower right of each figure show a predominant inundation flow direction roughly estimated by each tsunami-race distribution. The proposed method for estimating inundation flow velocity assumes that tsunami-traces are formed by run-up tsunamis. Therefore, it is necessary to judge whether tsunami-traces around buildings are affected by reflected flows or return flows of tsunamis. Matsutomi and Okamoto (2010) proposed a criterion for judging it, based on field surveys and laboratory experiments. The criterion is $h_{f} / h_{r} \geq 1.3$ and $F_{r}\left(=u / \sqrt{g h_{r}}\right) \geq 0.42$. When both parameters are smaller than these values, it is judged that tsunami-traces around buildings are affected by reflected flows or return flows of tsunamis. For example, in the case of Fig. $7(\mathrm{c}),\left(h_{f}-h_{r}\right)$ is $(4.0-3.12) \mathrm{m}=0.88$ $\mathrm{m}, h_{f}$ is $[4.0-\{(4.0-1.92)+(3.12-1.41)\} / 2] \mathrm{m} \cong 2.10 \mathrm{~m}, h_{r}$ is $[3.12-\{(4.0-1.92)+(3.12-1.41)\} / 2] \mathrm{m} \cong 1.22$ $\mathrm{m}$ and $R$ is $4.0 \mathrm{~m}$. Hence, $h_{f} / h_{r}$, inundation flow velocity $u$ and Froude number $F_{r}$ can be estimated as $1.7,4.2 \mathrm{~m} / \mathrm{s}$ and 1.2 respectively, when $C_{v}=1.0$ (no energy loss during inundation around a building) is assumed. They are $1.7,2.5 \mathrm{~m} / \mathrm{s}$ and 0.72 respectively, when $C_{v}=0.6$ is adopted. Therefore, it is judged that the tsunami-traces in Fig. 7(c) are not affected by reflected flows or return flows of tsunamis.

Figure 7 (a) shows tsunami-trace heights and their distribution around a building at Maloata, where ground slope along the arrow in the left of the figure is $-1 / 52$, foreshore slope is $-1 / 19$ and distance from the building to shoreline is $64 \mathrm{~m}$. Plane shape of the building is considerably complicated and 12 data were collected. It was estimated that $h_{f} / h_{r}$ was 1.9 , inundation flow velocity was $3.0 \mathrm{~m} / \mathrm{s}$ and Froude number was 0.79 at the maximum incident inundation depth.

Figure 7 (b) shows tsunami-trace heights and their distribution around a building at Amanave, where ground slope along the arrow in the left of the figure is $-1 / 40$, distance from the building to shoreline is $142 \mathrm{~m}$, and there is a scarp around $1 \mathrm{~m}$ high on the way. It was estimated that $h_{f} / h_{r}$ was 1.2 , inundation flow velocity was $1.7 \mathrm{~m} / \mathrm{s}$ and Froude number was 0.42 .

Figure 7 (c) shows tsunami-trace heights and their distribution around a building at Leone, where ground slope along the arrow in the left of the figure is $-1 / 220$, distance from the building to shoreline is $109 \mathrm{~m}$, and there is also a scarp around $1 \mathrm{~m}$ high on the way.

Figure 7 (d) shows tsunami-trace heights and their distribution around a building at Pago Pago, where ground slope and distance from the building to shoreline are $-1 / 30$ and $35 \mathrm{~m}$ respectively, and a scarp around $1.5 \mathrm{~m}$ high is formed at the shoreline. Pago Pago is located at the bottom of long, narrow, curved bay. Therefore, the tsunami-traces were affected by reflected flows or return flows of tsunamis $\left(h_{f} / h_{r}=1.2, F_{r}=0.33\right)$.

The inundation flows at the maximum incident inundation depth stated above except for the case of Fig. 7(d) are sub-critical flows $\left(F_{r}<1.0\right)$. This is consistent with the report on a sub-critical flow near the Putri's building in Banda Aceh in the 2004 Indian Ocean tsunami (Sakakiyama et al. 2005; Matsutomi et al. 2006) which was located at a flat low-lying place away from shoreline. 


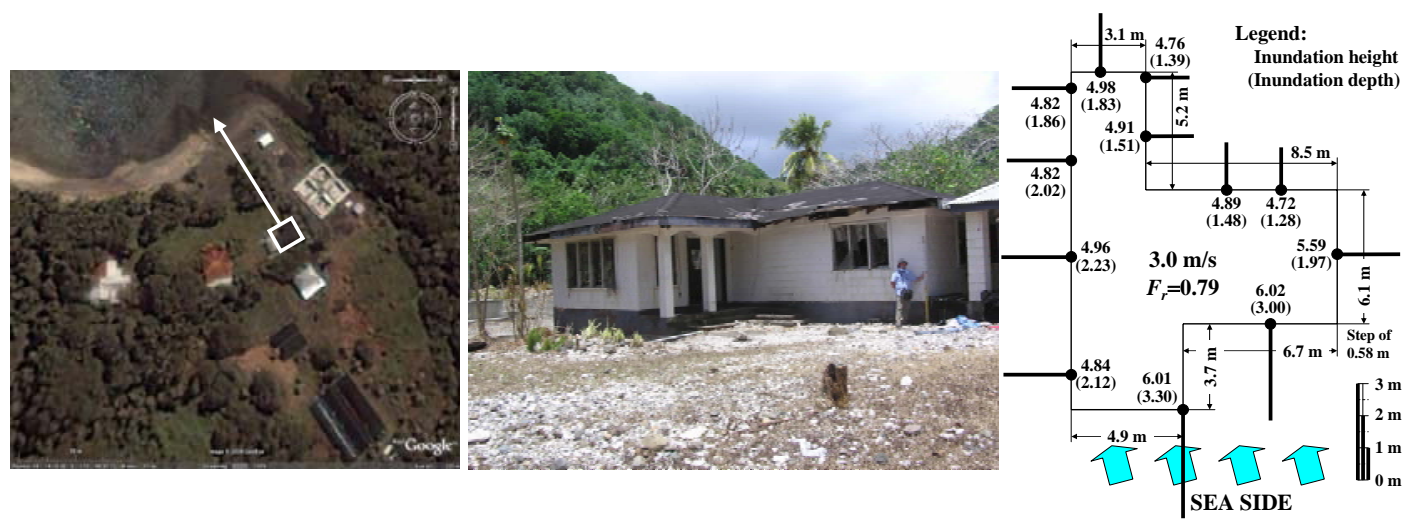

(a) Maloata

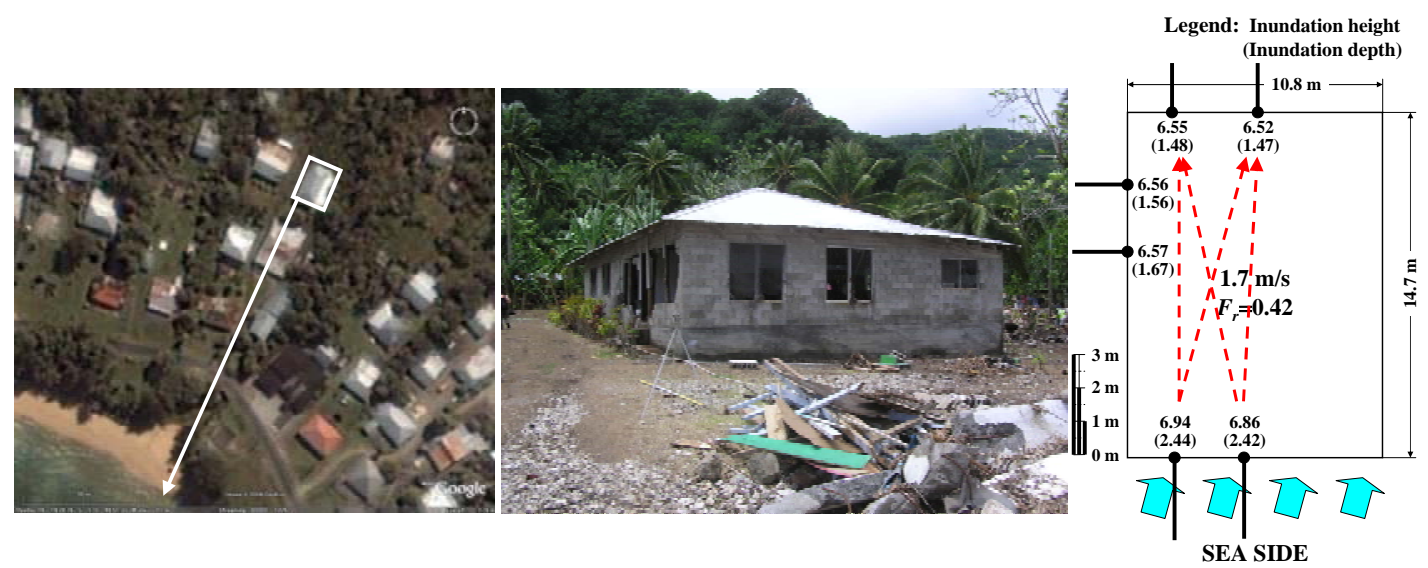

(b) Amanave

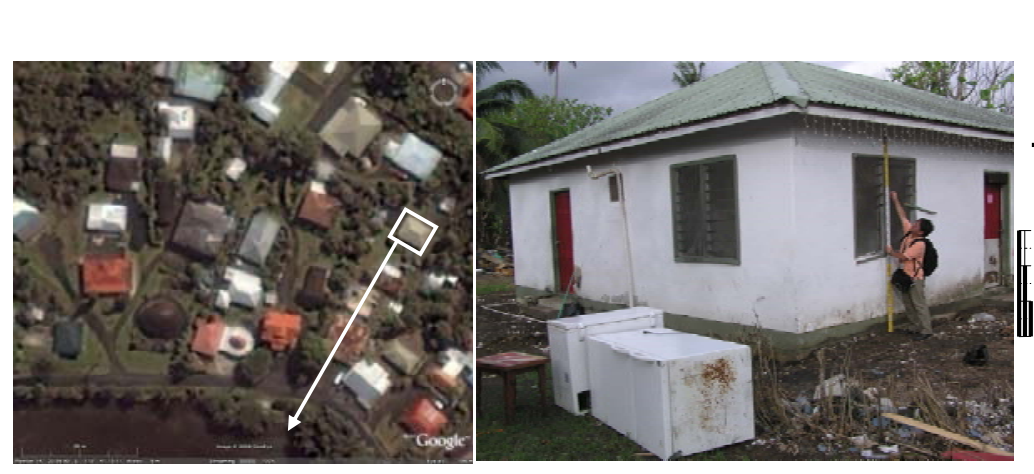

(c) Leone

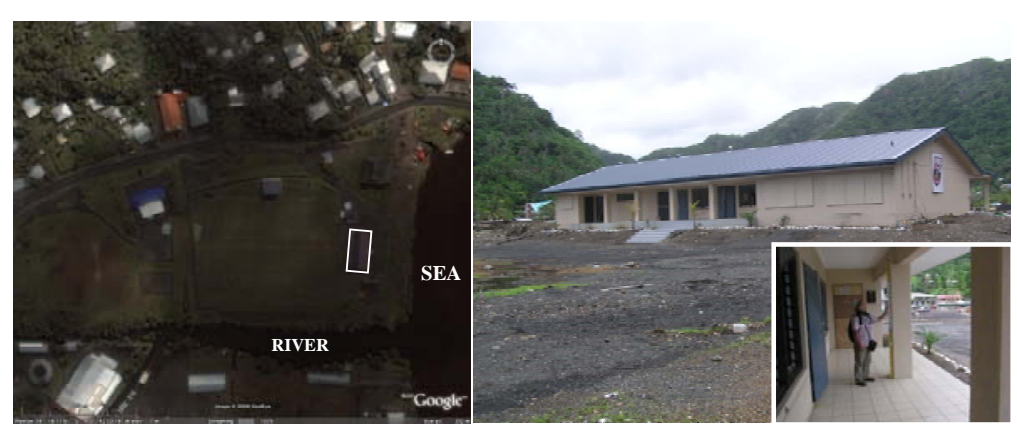

(d) Pago Pago

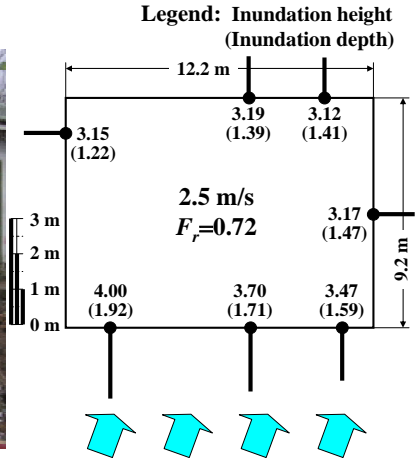

SEA SIDE

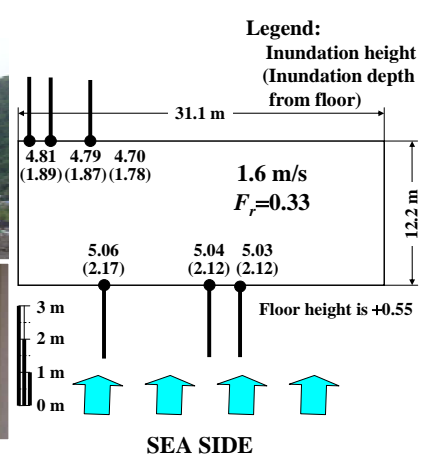

SEA SIDE

Figure 7. Tsunami-trace heights and their distributions around buildings in Tutuila Is., American Samoa in the 2009 Samoa Earthquake tsunami. 


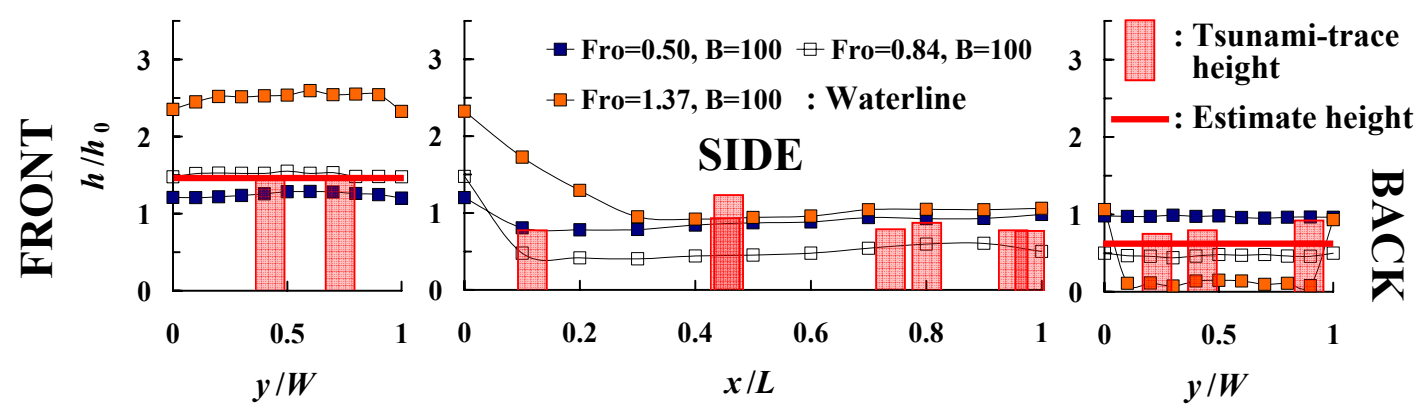

(a) Maloata $\left(F_{r 0} \cong 0.79\right)$

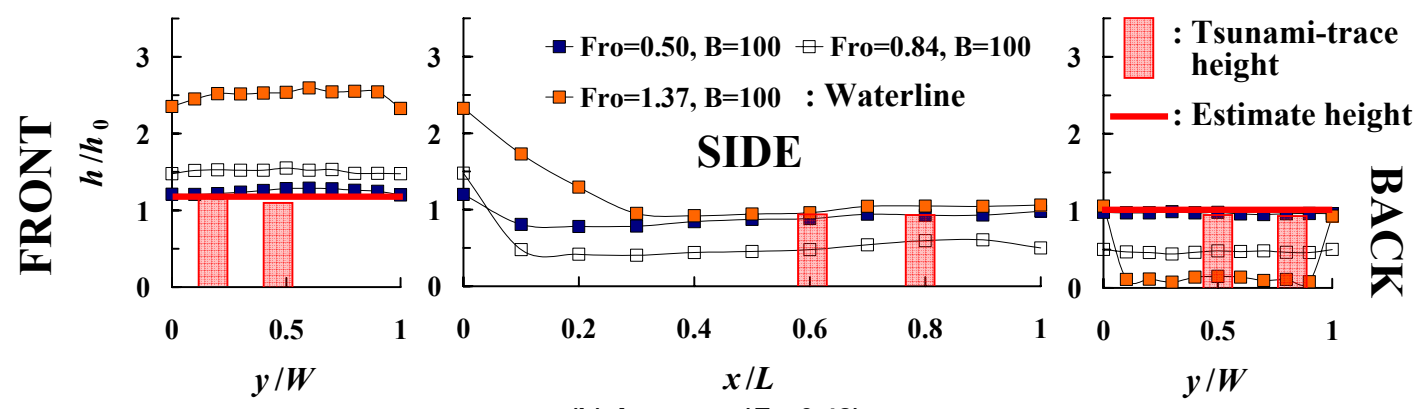

(b) Amanave $\left(F_{r 0} \cong 0.42\right)$

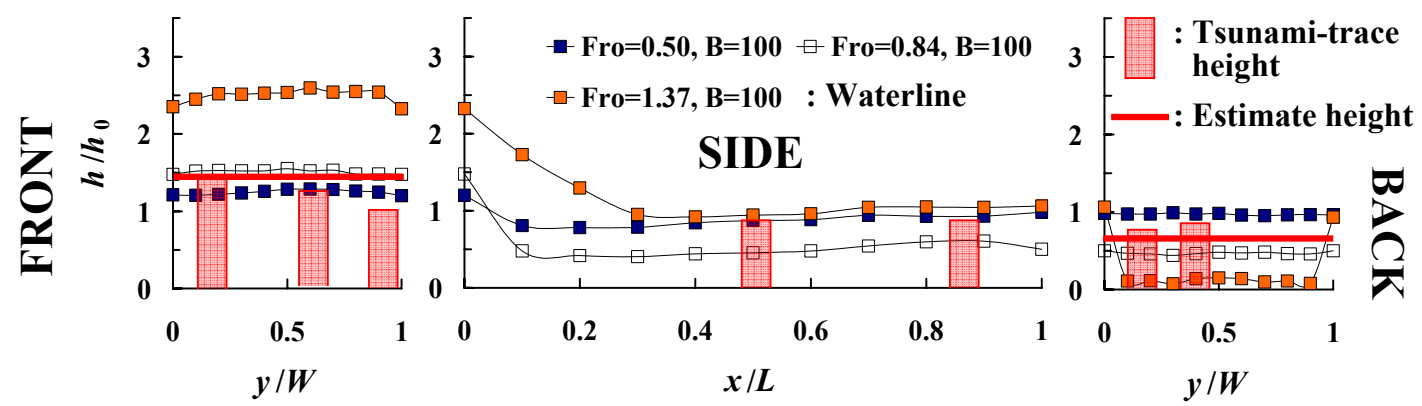

(c) Leone $\left(F_{r 0} \cong 0.72\right)$

Figure 8. Comparisons between tsunami-trace distribution around building in Tutuila Is., American Samoa in the 2009 Samoa Earthquake tsunami and waterline distribution around square pillar model by the steady flow experiments.

\section{Comparison between Experimental and Field Survey Results}

Figures 8(a)-(c) show comparisons between tsunami-trace distribution (vertical broad lines) around the building shown in Figs. 7(a)-(c) and waterline distribution (horizontal bold lines) around the square pillar model shown in Fig. 5, where the nondimensionalized maximum tsunami-trace and waterline heights at the fronts of building and model respectively are assumed to be the same each other. The nondimensionalized maximum waterline heights at the front of model are estimated using a linear interpolation or extrapolation method under the assumption of $F_{r 0}=F_{r}$. These assumptions and method make it possible to estimate uniform flow depths $h_{0}$ and then nondimensionalized inundation depths at the back of building in real inundation flows.

It is understood from the figures that the nondimensionalized inundation depths at the back of building by field surveys are a little bigger than those by steady flow experiments. The reasons seem to be that real inundation flows are unsteady and frequently flow into the front windows and/or doors of buildings and out from the back of those.

\section{Variation Coefficient C.V. of Inundation Flow Velocity}

Variation coefficient $C . V$. of inundation flow velocity $u$ estimated by Eq. 9 is examined using the tsunami-trace heights around buildings shown in Figs. $7(\mathrm{a})-(\mathrm{c}) .10(=2 \times 5), 4(=2 \times 2)$ and $6(=3 \times 2)$ inundation flow velocities are conceivable in order of the figures (see the dotted lines in Fig. 7(b)). The variation coefficient ranged $0.043,0.059$ and 0.20 in order of the figures. It is understood from this result and the inundation flow direction indicated in each figure that as incident angle of inundation flow to the front wall of building becomes large, the variation coefficient becomes large. 
Table 3. New judgment criterion for the degree of damage to buildings.

\begin{tabular}{|c|c|c|c|c|c|c|}
\hline \multirow{2}{*}{ Type of building } & \multicolumn{3}{|c|}{ Partially Damaged } & \multicolumn{3}{c|}{ Destroyed } \\
\cline { 2 - 7 } & $\begin{array}{c}h_{f} \\
(\mathrm{~m})\end{array}$ & $\begin{array}{c}u \\
(\mathrm{~m} / \mathrm{s})\end{array}$ & $\begin{array}{c}F_{D} \\
(\mathrm{kN} / \mathrm{m})\end{array}$ & $\begin{array}{c}h_{f} \\
(\mathrm{~m})\end{array}$ & $\begin{array}{c}u \\
(\mathrm{~m} / \mathrm{s})\end{array}$ & $\begin{array}{c}F_{D} \\
(\mathrm{kN} / \mathrm{m})\end{array}$ \\
\hline $\begin{array}{c}\text { Reinforced } \\
\text { Concrete }\end{array}$ & - & - & - & $>8.0$ & $>5.8$ & $>155 \sim 281$ \\
\hline $\begin{array}{c}\text { Stone, Bricks, } \\
\text { Concrete Block }\end{array}$ & 3.0 & 3.6 & $21.8 \sim 39.6$ & 7.0 & 5.5 & $118 \sim 215$ \\
\hline Wood & 1.5 & 2.5 & $5.4 \sim 9.9$ & 2.0 & 2.9 & $9.7 \sim 17.6$ \\
\hline $\begin{array}{l}\text { Degree of } \\
\text { Damage }\end{array}$ & \multicolumn{3}{|l|}{$\begin{array}{l}\text { Most pillars withstand tsunami, } \\
\text { but parts of walls are damaged. } \\
\text { Restoration is possible. }\end{array}$} & $\begin{array}{l}\text { Walls and most of pillars are } \\
\text { damaged. Restoration is not } \\
\text { possible. }\end{array}$ \\
\hline
\end{tabular}
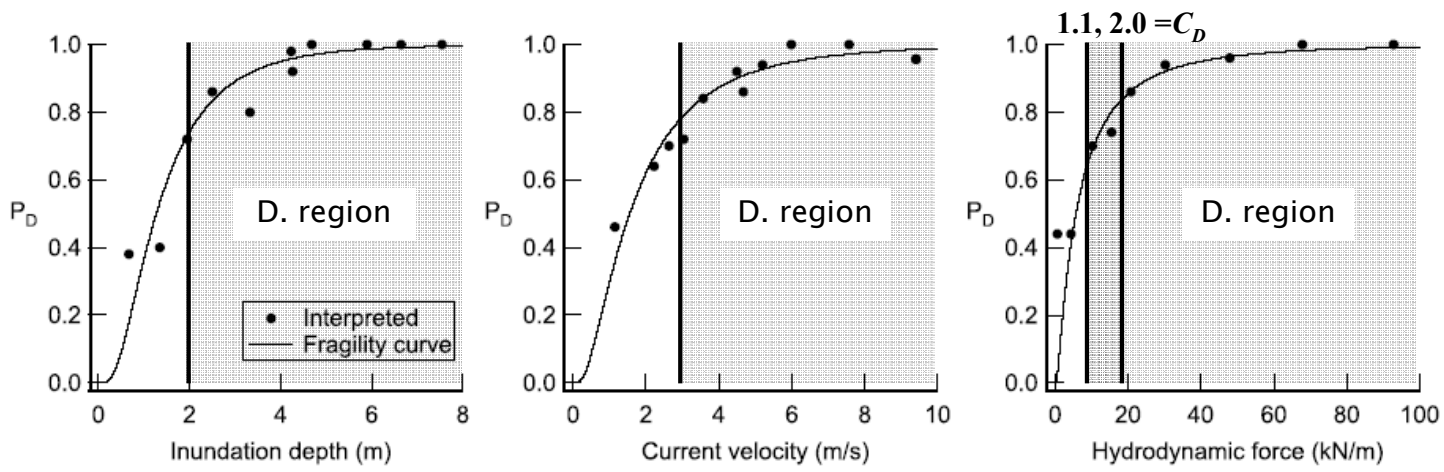

Figure 9. Comparisons between new judgment criterion for the degree of damage to wooden buildings (shaded: Destroyed) and the tsunami fragility curve for Japanese wooden buildings by Koshimura et al. (2009)

\section{JUDGMENT CRITERION FOR DEGREE OF DAMAGE TO BUILDINGS}

It has been tried to simply and practically express judgment criterion for the degree of damage to buildings in inundation depth, inundation flow velocity and drag force $F_{D}$ (e.g., Matsutomi and Shuto 1994; Iizuka and Matsutomi 2000; Matsutomi 2009b). Except for a short time of collision of a tip region of bore or inundation flow, drag force is dominant in fluid force acting on buildings (Matsutomi 1991). By assuming very severe case to buildings, and taking the wave period of tsunamis into consideration, Eq. 10 or 12 was proposed as a simple and practical relationship between tsunami inundation flow velocity and inundation depth, which exerts the largest fluid force. Equation 10 or 12 leads to Eq. 14 for drag force $F_{D}$ acting on buildings and new judgment criterion for the degree of damage to buildings shown in Table 3:

$$
F_{D}=0.22 \gamma_{s} C_{D} h_{f}^{2} W
$$

where $\gamma_{s}\left(=10.1 \mathrm{kN} / \mathrm{m}^{3}\right)$ is unit weight of fluid, $C_{D}$ is drag coefficient and $W$ is width of a rectangular building with vertical walls. $C_{D}(=1.1-2.0)$ depends on plane shape of building and incident angle of inundation flow to building. Figure 9 shows comparisons between new judgment criterion for the degree of damage to wooden buildings and the tsunami fragility curve $P_{D}$ for Japanese wooden buildings by Koshimura et al. (2009). It is concluded from the figure that both are consistent each other.

\section{CONCLUSIONS}

Main results in this study are that:

- Assuming very severe case to structures, and taking the wave period of tsunamis into consideration, the velocity coefficient $C_{v}=0.6$ is recommended as its simple and practical value.

- Based on the field data of inundation depths $h_{f}$ and $h_{r}$, inundation flow velocity $u$ estimated using Bernoulli's theorem and inundation depths, and $C_{v}=0.6$, two simple and practical relationships between inundation flow velocity and inundation depth (Eqs. 10 and 11 or Eqs. 12 and 13) were proposed for two cases where inundation flow velocity exerts the largest or the smallest fluid force on structures. 
- Field data indicate that Froude number, defined by $F_{r}=u / \sqrt{g h_{r}}$ where $u=\sqrt{2 g\left(h_{f}-h_{r}\right)}$, ranges 0.7-2.0. When $C_{v}=0.6$ is adopted, Froude number ranges 0.42-1.2.

- Fundamental characteristics of the waterline distribution around the typical object model (square pillar model) were examined through the steady flow experiments. It was confirmed that $h_{r} \cong h_{0}$ when Froude number, defined by $F_{r 0}=u_{0} / \sqrt{g h_{0}}$ where $u_{0}$ and $h_{0}$ were uniform flow velocity and depth respectively, was much less than 1.0 .

- Tsunami-trace distributions around buildings by field surveys are consistent with those by laboratory experiments.

- Variation coefficient C.V. of the inundation flow velocity $u$ estimated using the proposed method and field data of inundation depths ranged 0.043-0.20. It was confirmed that as incident angle of inundation flow to the front wall of building became large, the variation coefficient became large.

- New judgment criterion for the degree of damage to buildings was presented and it was confirmed that the new judgment criterion for the degree of damage to wooden buildings was consistent with the tsunami fragility curve for Japanese wooden buildings by Koshimura et al. (2009).

\section{ACKNOWLEDGMENTS}

This work was supported by the Grant-in-Aid for Scientific Research from the Japan Society for the Promotion of Science (No. 21510187), and the North Tohoku universities of Akita, Hirosaki and Iwate, and Science and Technology Research Partnership for Sustainable Development from the Japan Science and Technology Agency, the Japan International Cooperation Agency, the State Ministry of Research and Technology of Indonesia and the Indonesian Institute of Science.

\section{REFERENCES}

Iizuka, H., and H. Matsutomi. 2000. Damage due to inundation flow of tsunami, Proceedings of Coastal Engineering, JSCE, 47, 381-385. (in Japanese)

Koshimura, S., M. Matsuoka, and S. Kayaba. 2009. Tsunami hazard and structural damage inferred from the numerical model, aerial photos and SAR imageries, Proceedings of $7^{\text {th }}$ International Workshop on Remote Sensing for Post Disaster Response (CD-ROM).

Matsutomi, H. 1991. An experimental study on pressure and total force due to bores, Proceedings of Coastal Engineering, JSCE, 38, 626-630. (in Japanese)

Matsutomi, H. 1999. A practical formula for estimating impulsive force due to driftwoods and variation features of the impulsive force, Journal of Hydraulic, Coastal and Environmental Engineering, JSCE, 621/II-47, 111-127. (in Japanese with English abstract)

Matsutomi, H. 2009a. Method for estimating collision force of driftwood accompanying tsunami inundation flow, Journal of Disaster Research, 4, 435-440.

Matsutomi, H. 2009b. Problems in recent onshore and land tsunamis, Lecture Notes of the $45^{\text {th }}$ Summer Seminar on Hydraulic Engineering, 2009, Course B, JSCE, B-3-1-20.

Matsutomi, H., and H. Iizuka. 1998. Tsunami current velocity on land and a simple method for estimating it, Proceedings of Coastal Engineering, JSCE, 45, 361-365. (in Japanese)

Matsutomi, H., and K. Okamoto. 2010. Inundation flow velocity of tsunami on land, Island Arc, 19, Issue 3, 443-457.

Matsutomi, H., and N. Shuto. 1994. Tsunami inundation depth, current velocity and damage to houses, Proceedings of Coastal Engineering, JSCE, 41, 246-250. (in Japanese)

Matsutomi, H., M. Fujii, and T. Yamaguchi. 2009. Experiments and development of a model on the inundated flow with floating bodies, Proceedings of the $31^{\text {st }}$ International Conference on Coastal Engineering, ASCE, 2, 1458-1470.

Matsutomi, H., K. Harada, T. Ogasawara, and S. Kataoka. 2010. A side of the 2010 Chile Earthquake tsunami, Proceedings of the $29^{\text {th }}$ Annual meeting, JSNDS. (in Japanese)

Matsutomi, H., T. Sakakiyama, S. Nugroho, and M. Matsuyama. 2006. Aspects of inundated flow due to the 2004 Indian Ocean tsunami, Coastal Engineering Journal, 48, 167-195.

Sakakiyama, T., H. Matsutomi, Y. Tsuji, and Y. Murakami. 2005. Comparison of tsunami inundation flow velocities based on analysis of video pictures and field survey, Tsunami Engineering Technical Report, Tohoku University, 22, 111-117. (in Japanese)

Shuto, N., F. Imamura, S. Koshimura, K. Satake, and H. Matsutomi. 2007. Encyclopedia of tsunamis, Asakura Publishing Co., Ltd., Tokyo, 350 pp. (in Japanese)

USGS. 2009. Magnitude 8.1 - SAMOA ISLANDS REGION. http://earthquake.usgs.gov/eqcenter/ eqinthenews/2009/us2009mdbi/ 